\title{
Apoptosis in lung injury and fibrosis
}

\author{
F. Drakopanagiotakis*, A. Xifteri*, V. Polychronopoulos* and D. Bouros ${ }^{\#}$
}

\begin{abstract}
Pulmonary fibrosis is characterised by fibroblast accumulation and alveolar epithelium denudation. Increased apoptosis of alveolar epithelial cells and decreased apoptosis of fibroblasts may play an important role in the pathogenesis of disease. Inflammatory cells can modulate apoptosis of other cell types, both by removal of apoptotic debris and by cytokine production, thus preserving a pro-fibrotic environment. In the present review, some of the mechanisms by which apoptosis may contribute to the pathogenesis of idiopathic pulmonary fibrosis are described.
\end{abstract}

KEYWORDS: Apoptosis, epithelium, fibroblast, mechanisms, pathogenesis, pulmonary fibrosis

(1) diopathic pulmonary fibrosis (IPF) is a chronic diffuse lung disease characterised by progressive deterioration in lung function ultimately leading to death. The histological pattern of IPF is usual interstitial pneumonia (UIP), described as the patchy presence of denuded alveolar epithelium, fibroblastic foci and distortion of lung architecture leading to honeycombing with minimal inflammation. It has been proposed that epithelium-fibroblast interactions may lead to alveolar cell loss and the initiation of the fibrotic process [1].

Apoptosis, or programmed cell death, is an important physiological process for the development and the maintenance of tissue homeostasis, ensuring a balance between cellular proliferation and turnover in nearly all tissue types.

Apoptosis may participate in the development of lung disease via three different mechanisms: 1) increased apoptosis of epithelial cells leading to inefficient re-epithelialisation [2]; 2) resistance to apoptosis of fibroblasts leading to increased fibrosis [2]; and 3) ineffective removal of apoptotic cells (efferocytosis) by granulocytes sustaining a persistent inflammatory state [3].

Although significant progress has been made with regard to the understanding of the mechanisms involved in the development of pulmonary fibrosis, the pathogenesis of the disease is not yet clear. An important part of the present knowledge has arisen from animal models, such as the bleomycin-induced pulmonary fibrosis model. However, this model has certain limitations, specifically the differences in chronicity and pathogenesis between this model and IPF. In the murine bleomycin model, acute alveolitis develops with significant inflammation followed by fibrosis in a short period of time, unlike the indolent fibrosis and minimal inflammation seen in human IPF [4].

The aim of the present review is to characterise the importance of apoptosis as a potential pathogenic mechanism in the development of pulmonary fibrosis and its relationship with other pathogenic processes.

\section{MECHANISMS OF APOPTOSIS}

Apoptotic cells undergo various morphological changes, including cell shrinkage, membrane blebbing, cleavage of chromosomal DNA and the release of the membrane-bound apoptotic bodies. Apoptosis mechanisms involve: 1) the initiation phase, during which apoptotic stimuli lead to caspase activation; and 2) the execution phase, during which caspases induce cell death.

The caspase cascade can be activated by different pathways (fig. 1) [5].

\section{The extrinsic or death receptor pathway}

The extrinsic or death receptor pathway involves the activation of death receptors present in the cell membrane, such as Fas and tumour necrosis factor (TNF) receptor 1. Connection of the death ligand to its death receptor leads to activation of an adaptor protein called activated death domain and the subsequent activation of procaspase- 8 or -10. Activated caspases induce apoptosis. The extrinsic pathway can be inhibited by at least three mechanisms: 1) FLIP (Fas-activated death domain (FADD)-like interleukin-1 converting enzyme (FLICE)-like inhibitor of apoptosis protein), which binds to procaspase- 8 without
AFFILIATIONS

*Interstitial Lung Disease Study Group, 3rd Dept of Pneumonology, Sismanoglio General Hospital, Athens, and

"Dept of Pneumonology, University Hospital of Alexandroupolis and Medical School, Democritus University of Thrace, Alexandroupolis, Greece.

CORRESPONDENCE

D. Bouros

Hellenic Interstitial Lung Disease Group

Dept of Pneumonology

Medical School Democritus University of Thrace

University General Hospital 68100 Alexandroupolis Greece

Fax: 302106001213

E-mail: bouros@med.duth.gr

Received:

December 312007

Accepted after revision:

August 062008

STATEMENT OF INTEREST

None declared. 


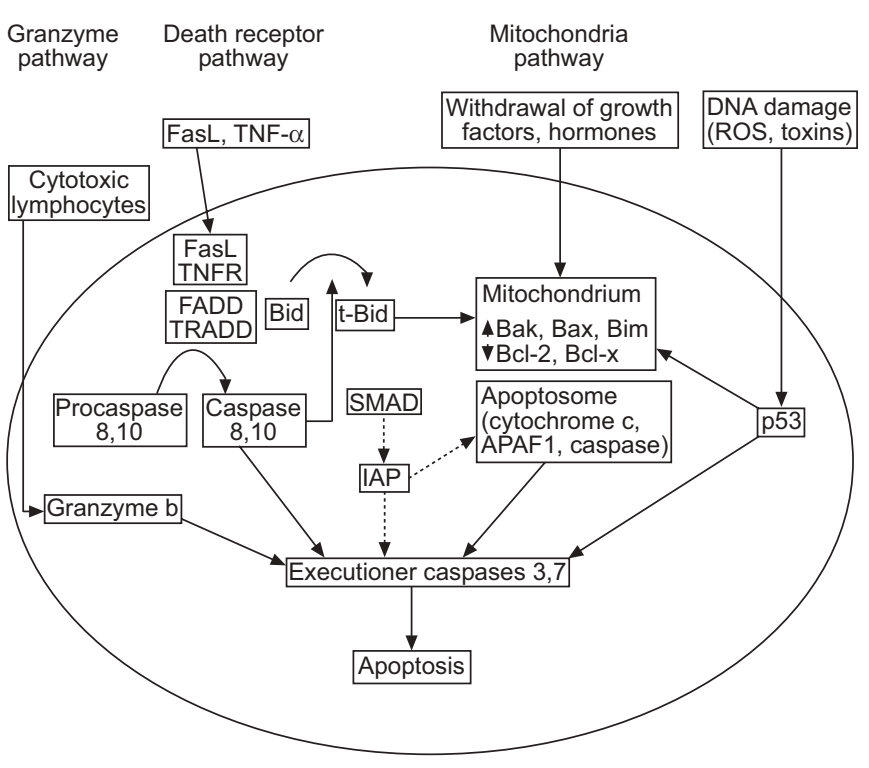

FIGURE 1. Different pathways leading to caspase cascade activation and apoptosis. FasL: Fas ligand; TNF: tumour necrosis factor; ROS: reactive oxygen species; TNFR: TNF receptor; FADD: Fas activated death domain; TRADD: TNF- $\alpha$ activated death domain; APAF: apoptotic protease activating factor; IAP: inhibitor of apoptosis. Dotted arrows represent inhibitory pathways.

activating it; 2) the binding of decoy receptors that antagonise membrane death receptors for death ligand binding; and 3) by the heat shock proteins [6].

\section{The intrinsic pathway}

The intrinsic pathway is due to an increase of mitochondrial permeability and is activated by cellular "stresses". Various stress factors lead to reduced expression of anti-apoptotic mitochondrial proteins (e.g. B-cell lymphoma (Bcl)-2 and Bcl-x) and to increased expression of pro-apoptotic mitochondrial proteins (e.g. Bak, Bax, Bim) [7]. Other pro-apoptotic factors such as Smac (second mitochondria-derived activator of caspase)/DIABLO (direct inhibitor of apoptosis protein-binding protein with low pI), apoptosis-inducing factor and endonuclease $\mathrm{G}$ are also released from the mitochondria [8].

\section{Granzyme B pathway}

Cytotoxic lymphocytes, after encountering infected or malignancy-transformed host cells, secrete perforin, a protein capable of creating pores in the cell membrane of the infected cell, through which granzyme B, a serine protease, invades the host cell and induces apoptosis [9].

\section{CELLULAR APOPTOTIC PROFILE IN PULMONARY FIBROSIS}

\section{Alveolar epithelial cells}

Alveolar epithelium contains a continuous layer of two cell types: the flattened type-I pneumocytes, which cover $95 \%$ of the alveolar surface, and the type-II pneumocytes. Type-II pneumocytes can proliferate and generate both type-II and type-I cells. Moreover, they can secrete a number of molecules, such as surfactant-associated products, cytokines and growth factors, enzymes and matrix proteins [1].
Alveolar epithelial cell (AEC) apoptosis, with subsequent fibrosis, is documented in the bleomycin-induced fibrosis model of IPF [10]. Additionally, the activation of the Fas-Fas ligand (FasL) pathway also promotes pulmonary fibrosis [11]. Furthermore, AEC apoptosis is induced by transferring myofibroblasts from fibrotic lungs that overexpress FasL molecules into healthy murine lungs; likewise, FasL-deficient myofibroblasts do not express this cytotoxic potential [12]. Blockade of either the Fas-FasL pathway or caspase inactivation by caspase inhibitors has been shown to prevent AEC apoptosis and pulmonary fibrosis [13, 14].

In lung biopsies of patients with IPF, AECs exhibit positive signals for apoptosis [15], such as p53 and p21, especially in areas adjacent to fibroblasts [16]. p53 (a regulator of the cell cycle and trigger of apoptosis in response to DNA damage) is over expressed in AECs of patients with IPF [15], perhaps due to decreased degradation [17]. p21 gene (an inducer of G1 arrest and DNA repair) is shown to protect AECs from apoptosis in the bleomycin-induced murine lung model of fibrosis [18]. Apoptotic hyperplastic epithelial cells are present in patients with IPF, and the expression of p53, p21, Bax and caspase-3 appears to be upregulated, while Bcl-2 is downregulated (table 1) [19].

\section{Fibroblasts}

Fibroblasts synthesise and deposit collagen and other extracellular matrix components within the fibrotic lesions of UIP [1]. During normal wound healing, fibroblast number is reduced by apoptosis [20].

IPF fibroblasts have been reported to be resistant to Fasmediated apoptosis [21]. Resistance is attributed to the increased expression of X-linked inhibitor of apoptosis and FLIP proteins [22], as well as to decreased levels of surface Fas and increased levels of soluble Fas [23]. The expression of discoid-domain receptor I, a tyrosine kinase whose ligand is collagen, is increased in fibroblasts of mice with bleomycininduced fibrosis and it promotes resistance to apoptosis [24].

Transforming growth factor (TGF)- $\beta 1$, the main pro-fibrotic cytokine, independently activates the two important antiapoptotic pathways in lung fibroblasts: the focal adhesion kinase (FAK) pathway by activation of Smad3 and the phosphatidylo-inositol 3 kinase (PI3K)/Akt pathway via activation of p38 mitogen-activated protein kinase [25].

Thy-1, a cell surface glucoprotein, has been associated with increased apoptosis of lung fibroblasts. It has been shown that the myofibroblasts of fibroblastic foci are Thy- 1 negative and that Thy-1 negativity offers apoptosis resistance (table 2) [26].

\section{Macrophages}

Macrophage activation has been implicated in the pathogenesis of fibrotic lung diseases, such as the Hermansky-Pudlak syndrome [27]. Bleomycin has been shown to induce alveolar macrophage apoptosis in experimental models [28, 29], while intratracheal administration of apoptotic macrophages to the lungs of rats causes increased macrophage infiltration and apoptosis, and increased collagen deposition [30, 31]. Increased macrophage expression of Bcl-x and Bax proteins, as well as caspases-1 and -3 in bleomycin-induced fibrosis [14, 32], and 


\section{TABLE 1 Factors associated with increased alveolar epithelial cell apoptosis in idiopathic pulmonary fibrosis}

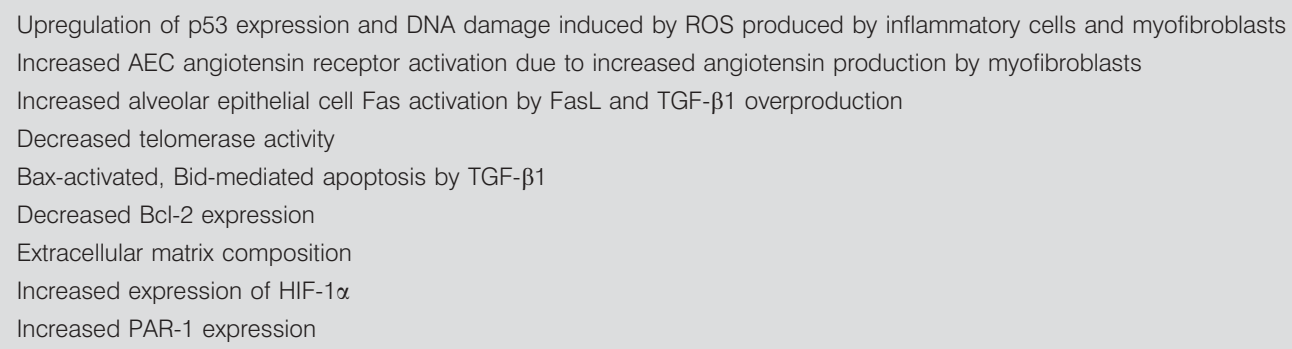

ROS: reactive oxygen species; AEC: alveolar epithelial cells; FasL: Fas ligand; TGF: transforming growth factor; Bcl: B-cell lymphoma; HIF: hypoxia-inducible factor; PAR: protease-activating receptor.

Bcl-2 and Fas expression in alveolar macrophages of patients with IPF, has been reported [33, 34].

Moreover, mice deficient in macrophage colony-stimulating factor (M-CSF), a factor associated with the survival of macrophages, develop less pulmonary fibrosis and have a decreased number of macrophages in their lungs after bleomycin installation. M-CSF levels are significantly higher in patients with IPF compared with normal subjects [35]. Macrophages can also inhibit myofibroblast apoptosis through the release of insulin-like growth factor-1 by macrophages (table 3) [36].

\section{Neutrophils}

Although impaired neutrophil apoptosis has been associated with a number of respiratory diseases [37], its role in the pathogenesis of IPF is not clearly understood. The presence of increased numbers of neutrophils in the lungs of patients with IPF is associated with dismal prognosis [38]. The anti-apoptotic protein Bcl-2 is significantly upregulated in the neutrophils of patients with IPF [34].

Corticosteroids, although minimally active as a therapeutic option in IPF, have been shown to significantly increase the rate of neutrophil apoptosis, while simultaneously reducing the rate of alveolitis and subsequent fibrosis in rats after instillation of bleomycin [39]. However, others have reported that neutrophilia is not associated with poorer clinical course and that bleomycin-induced fibrosis is enhanced in the absence of neutrophils [40, 41].

\section{TABLE 2 Factors associated with decreased fibroblast apoptosis in idiopathic pulmonary fibrosis}

Resistance to Fas-mediated apoptosis

Increased expression of anti-apoptotic proteins: IAP, FLIP

Increased Bcl-2 expression

Extracellular matrix composition

Activation of the FAK and PI3K pro-survival pathways by TGF- $\beta 1$

IAP: inhibitor of apoptosis; FLIP: Fas-activated death domain-like interleukin-1 converting enzyme-like inhibitor of apoptosis protein; Bcl: B-cell lymphoma FAK: focal adhesion kinase; PI3K; phosphatidylo-inositol 3 kinase; TGF transforming growth factor.
The uncertainty of whether the neutrophilic accumulation in the end stages of disease is a significant pathogenic mechanism or an epiphenomenon of advanced fibrotic disease highlights current uncertainties about the pathogenesis of IPF. Currently, inflammation is not thought to play a major pathogenic role in IPF [1, 2]. In advanced disease, an influx of neutrophils might result from either sub-clinical infection in destroyed lung or the fibrogenetic secretion of chemotactic factors. However, it is also possible that neutrophils may play a primary pathogenic role in acute exacerbations of IPF [42], which may account for a neutrophil influx in some cases.

\section{INTERRELATIONSHIPS BETWEEN APOPTOSIS AND OTHER PULMONARY FIBROSIS MECHANISMS}

Pathogenesis of pulmonary fibrosis remains a complicated issue. Numerous pathogenic mechanisms are implicated and interrelate, resulting in significant difficulty in discriminating which are the primary and secondary events in the development of the disease. In a recent review, it was proposed that injury due to various agents (chronic viral infections, cigarette smoke, gastro-oesophageal reflux disease and exposure to environmental pollutants) activates multiple pathways (oxidant-antioxidant, coagulation, inflammation and T-helper cell (Th) type $1 /$ Th2 cytokines) and causes an imbalance between pro-fibrotic (TGF- $\beta$, connective tissue growth factor and thrombin) and anti-fibrotic molecules (interferon- $\gamma$ and prostaglandin $E_{2}$ ). This imbalance induces a change in cellular function, expressed as altered apoptotic cell behaviour and proliferation, epithelial-mesenchymal transition and increased extracellular matrix production, ultimately leading to fibrosis [42]. In the following section, the interrelationships of apoptosis with other fibrotic mechanisms will be reviewed.

\section{Vasoconstrictors}

It has been shown in vitro and in animal models that vasoconstrictors participate in the development of fibrosis. Two of the most extensively studied vasoconstrictors are endothelin-1 and angiotensin-II. Although usually associated with resistance to apoptosis [43], endothelin-1 promotes epithelial-mesenchymal transition (the acquisition of mesenchymal phenotypic characteristics by epithelial cells) in IPF [44], while angiotensin peptides actively participate in apoptosis.

Angiotensin peptides are locally produced both by apoptotic AECs and by adjacent myofibroblasts [45]. AEC apoptosis is 


\section{TABLE 3 Putative mechanisms of macrophage participation in apoptosis in idiopathic pulmonary fibrosis}

Impaired removal of apoptotic cell remnants (efferocytosis)

Induction of normal macrophage cell death by apoptotic macrophages

Induction of AEC apoptosis by cytokines and growth factor secreted by macrophages (e.g. TGF- $\beta 1$ and TNF- $\alpha$ )

Inhibition of myofibroblast apoptosis through the release of insulin-like growth factor

AEC: alveolar epithelial cell; TGF: transforming growth factor; TNF: tumour necrosis factor

induced via Fas activation by angiotensin-II, which is produced by human lung fibroblasts $[46,47]$, and it can be attenuated by the administration of the angiotensin-converting enzyme inhibitor captopril [48], by the selective angiotensin type 1 receptor antagonist losartan [49] or by antisense oligonucleotides against angiotensinogen mRNA [50].

\section{Oxidative stress}

Oxidative stress has been thought to significantly contribute to epithelial cell damage in IPF [51]. Although the source of reactive oxygen species (ROS) in the lung is considered to be inflammatory cells, myofibroblasts can also produce hydrogen peroxide, which can, in turn, induce epithelial cell death [52]. Bleomycin induces AEC apoptosis and fibrosis by an increase of ROS [53], and free radical scavengers decrease the rate of apoptosis and pulmonary fibrosis [54]. Bleomycin-induced apoptosis has been associated with p53 translocation from the cytosol to the nucleus, caused by ROS in macrophages [55].

Oxidative stress also affects fibroblast apoptosis: hydrogen peroxide causes apoptosis of fibroblasts stimulated to proliferate or migrate to the wound [56].

\section{Hypoxia}

Lack of oxygen significantly disturbs AEC function, triggers apoptosis and promotes inflammation. Hypoxia-inducible factor (HIF)-1 is a major regulator of hypoxic signalling and is overexpressed in patients with IPF.

HIF- $1 \alpha$ causes increased epithelial cell apoptosis via Bnip 3L activation, a member of the bcl 2 family. Blockade of HIF-1 $\alpha$ or Bnip3L (Bcl-2/adenovirus E1B 19-kDa interacting protein 3L) significantly attenuates hypoxia-induced epithelial cell apoptosis [57]. Expression of HIF-1 $\alpha$ has been shown to be an early event in IPF and to correlate with activation of p53 and increased AEC apoptosis in lungs of patients with IPF and in bleomycin-induced fibrosis. HIF- $1 \alpha$ is absent in fibroblastic foci, whereas the anti-apoptotic protein Bcl-2 is increasingly expressed, further supporting the hypothesis of increased AEC apoptosis concomitantly with decreased fibroblast apoptosis [58].

\section{Extracellular matrix}

Increased extracellular matrix deposition is a hallmark of IPF and is associated with a dysregulation of matrix metalloproteases (MMPs) and their inhibitors [2].

The integrity of the basement membrane offers survival signals for adherent epithelial cells, while disruption of the adhesion leads to apoptotic cell death. The extracellular matrix may dictate the apoptotic profile of AECs. When cultured on laminin/collagen mixtures, epithelial cells undergo apoptosis, while culture on fibronectin or fibrin causes epithelialmesenchymal transition [59].

Matrix composition can lead to different apoptotic fibroblast responses [60]. Soluble fibronectin peptides can promote fibroblast apoptosis by disruption of adhesion via activation of the integrin-FAK survival pathway [61]; however, fibronectin can also reduce fibroblast apoptosis via activation of the PI3K pathway [62].

\section{TGF- $\boldsymbol{\beta 1}$}

Overproduction of TGF- $\beta 1$, a growth factor essential for wound healing, can result in excessive deposition of scar tissue and fibrosis [63]. TGF- $\beta 1$ directly induces epithelial cell apoptosis via Fas and caspase- 3 activation, and by enhancing the FasL-Fas interaction [64], while mice transfection with soluble TGF type-II receptors significantly attenuates the degree of apoptosis and pulmonary fibrosis [65].

Bid, another Bcl-2 family member is required for AEC apoptosis and bleomycin-induced fibrosis in mice after TGF$\beta 1$ activation as Bid-deficient mice are protected from developing fibrosis [66]. The Bax-mediated, Bid-activated pathway has recently been shown to be involved in the pathogenesis of pulmonary fibrosis. TGF- $\beta 1$ significantly stimulates Bax and Bid expression and causes the release of MMP-12 and tissue inhibitor of metalloprotease-1 in mice [67].

TGF- $\beta 1$ causes increased $\mathrm{p} 21$ expression in AECs via a TNF- $\alpha$ signalling pathway and absence of p21 expression is associated with increased TGF- $\beta 1$-induced fibrosis and epithelium apoptosis [68].

TGF- $\beta$ receptor type-I inhibitors are reported to decrease bleomycin-induced fibrosis and myofibroblast apoptosis [69]. As previously mentioned, TGF- $\beta$ activates the FAK and the PI3K/Akt anti-apoptotic pathways in lung fibroblasts [25].

\section{Inflammation}

Inflammation is not considered to be a major pathogenic component in the development of IPF. However, it plays a significant role in acute exacerbations of the disease and it may be necessary for the initiation of the fibrotic process [42].

Inflammation can lead to increased apoptosis. The proinflammatory cytokine TNF- $\alpha$ sensitises fibroblasts to Fasmediated apoptosis and interferon- $\gamma$, a Th1-type cytokine, can act synergistically with TNF- $\alpha$ for the enhancement of the apoptotic response [70].

Neutrophils can also induce AEC apoptosis: infiltrating granulocytes in lung biopsies and bronchoalveolar lavage of patients with IPF expressed significantly higher levels of FasL 
compared with controls, and this was associated with an increased expression of Fas in the adjacent epithelium [33].

Failure to remove excessive numbers of apoptotic cells may induce a persistent inflammatory state. Macrophages are considered to be the professional phagocytes of apoptotic cells, which can engulf and deposit apoptotic remnants [3]. Macrophages ingesting apoptotic cells release the anti-inflammatory cytokines interleukin (IL)-10 and TGF- $\beta 1$, which act locally [71]. Furthermore, apoptotic cells can produce IL-10 and TGF- $\beta 1$, thus enhancing the phagocytic capacity of macrophages [72]. Macrophages which phagocytose apoptotic bodies can also release pro-apoptotic factors that induce apoptosis of adjacent cells [73]. However, cleavage of apoptotic remnants may also lead to inflammation enhancement [74]. Interestingly, dexamethasone has been reported to induce apoptosis of pulmonary inflammatory cells and reduce the extent of bleomycin-induced fibrosis [39].

\section{Pro-coagulant activity}

After tissue injury, activation of the coagulation cascade rapidly takes place in order to provide a provisional extracellular matrix for the repair process to occur [1]. In pulmonary fibrosis, excess extravascular coagulation has been found, largely due to the production of pro-coagulant molecules, such as tissue factor and plasminogen-activating inhibitors, by AECs [75]. Furthermore, anticoagulants can effectively attenuate pulmonary fibrosis in animal models [75] and, in a randomised clinical trial of patients with IPF, addition of anticoagulants to corticosteroids significantly reduced acute exacerbations of IPF and improved survival [76].

Apoptosis of AECs and subsequent basement membrane denudation is a signal for tissue repair and initiation of the coagulation cascade [75]. Moreover, it has been shown that pro-coagulants can initiate apoptosis. Activation of proteaseactivating receptor (PAR)-1, a high-affinity receptor for thrombin, induces alveolar epithelial cell apoptosis in vitro [77]. PAR-1 also contributes to fibrogenesis via activation of TGF- $\beta 1$ [78].

\section{AGEING, APOPTOSIS AND PULMONARY FIBROSIS}

Pulmonary fibrosis is an age-related process. IPF is a disease affecting older individuals [2]. Patients with hereditary forms of pulmonary fibrosis, such as Hermansky-Pudlak syndrome, also develop pulmonary fibrosis as they age [79]. Dysregulation of apoptosis pathways is implicated in aging. Senescent cells affect organ repair and structure and promote local inflammation [80].

Activation of the p53 pathway is a cardinal event in the process of cell senescence [80]. Activation of p53 has also been shown to occur in the apoptotic process observed in AECs of patients with IPF [15]. Increased AEC apoptosis in senescent rats exposed to hyperoxia and oxidative stress has been reported [81]. Senescent human fibroblasts are resistant to apoptosis and this resistance is associated with increased expression of the anti-apoptotic factor Bcl-2 and downregulation of caspase-3 [82].

Telomerase is a ribonucleoprotein enzyme that maintains telomere length and retains cellular and subsequent organism lifespan. Dysfunctional telomeres trigger cell cycle arrest or apoptosis in mice [83]. Mutations in telomerase components, associated with defective telomerase activity and shortened telomeres, have been found in some cases of IPF [84] and telomerase regulation has been implicated in bleomycin-induced fibrosis. After bleomycin administration, AECs show a decreased telomerase activity in vitro, resulting in increased apoptosis, while in vivo telomerase activity increases in order to protect alveolar epithelium from bleomycin-induced apoptosis [85].

However, telomerase activity is required for fibrosis. Lung fibroblasts of mice with bleomycin-induced fibrosis with telomerase deficiency show decreased proliferation and increased apoptotic rates compared with controls, while restoration of telomerase activity results in increased lung fibrosis [86].

\section{CONCLUSION}

Accumulating evidence supports the importance of apoptosis as a potential pathogenic mechanism in idiopathic pulmonary fibrosis. Apoptosis can be either beneficial or detrimental to the organism. Different cell types exhibit different apoptotic behaviour. The pro-fibrotic environment induces epithelial cell apoptosis and increased myofibroblast survival. Inflammatory cells can modulate the fibrotic responses of the lung, both by self-apoptosis and removal of apoptotic debris. Targeting specific cell types with anti-apoptotic agents represents a major challenge in therapeutic intervention for debilitating diseases such as idiopathic pulmonary fibrosis. However, apoptosis is one of many mechanisms involved in the development of idiopathic pulmonary fibrosis and the complexity of interactions between these different mechanisms remains far from being resolved.

\section{ACKNOWLEDGEMENTS}

The authors would like to thank V. Fayngersh (Alpert Medical School, Brown University, Providence, RI, USA) for his valuable comments and for linguistic review of the paper.

\section{REFERENCES}

1 Selman M, King TE, Pardo A. Idiopathic pulmonary fibrosis: prevailing and evolving hypotheses about its pathogenesis and implications for therapy. Ann Intern Med 2001; 134: 136-151.

2 Antoniou KM, Pataka A, Bouros D, Siafakas NM. Pathogenetic pathways and novel pharmacotherapeutic targets in idiopathic pulmonary fibrosis. Pulm Pharmacol Ther 2007; 20: 453-461.

3 Vandivier RW, Henson PM, Douglas IS. Burying the dead: the impact of failed apoptotic cell removal (efferocytosis) on chronic inflammatory lung disease. Chest 2006; 129: 1673-1682.

4 Moore BB, Hogaboam CM. Murine models of pulmonary fibrosis. Am J Physiol Lung Cell Mol Physiol 2008; 294: L152-L160.

5 Martin TR, Hagimoto N, Nakamura M, Matute-Bello G. Apoptosis and epithelial injury in the lungs. Proc Am Thorac Soc 2005; 2: 214-220.

6 Beere HM. Death versus survival: functional interaction between the apoptotic and stress-inducible heat shock protein pathways. J Clin Invest 2005; 115: 2633-2639.

7 Ravagnan L, Roumier T, Kroemer G. Mitochondria, the killer organelles and their weapons. J Cell Physiol 2002; 192: 131-137. 
8 Susin SA, Lorenzo HK, Zamzami N, et al. Molecular characterization of mitochondrial apoptosis-inducing factor. Nature 1999; 397: 441-446.

9 Russell JH, Ley TJ. Lymphocyte-mediated cytotoxicity. Annu Rev Immunol 2002; 20: 323-370.

10 Hagimoto N, Kuwano K, Nomoto Y, Kunitake R, Hara N. Apoptosis and expression of Fas/Fas ligand mRNA in bleomycin-induced pulmonary fibrosis in mice. Am J Respir Cell Mol Biol 1997; 16: 91-101.

11 Hagimoto N, Kuwano K, Miyazaki H, et al. Induction of apoptosis and pulmonary fibrosis in mice in response to ligation of Fas antigen. Am J Respir Cell Mol Biol 1997; 17: 272-278.

12 Golan-Gerstl R, Wallach-Dayan SB, Amir G, Breuer R. Epithelial cell apoptosis by fas ligand-positive myofibroblasts in lung fibrosis. Am J Respir Cell Mol Biol 2007; 36: 270-275.

13 Kuwano K, Hagimoto N, Kawasaki M, et al. Essential roles of the Fas-Fas ligand pathway in the development of pulmonary fibrosis. J Clin Invest 1999; 104: 13-19.

14 Kuwano K, Kunitake R, Maeyama T, et al. Attenuation of bleomycin-induced pneumopathy in mice by a caspase inhibitor. Am J Physiol Lung Cell Mol Physiol 2001; 280: L316-L325.

15 Kuwano K, Kunitake R, Kawasaki M, et al. P21Waf1/Cip1/ Sdi1 and p53 expression in association with DNA strand breaks in idiopathic pulmonary fibrosis. Am J Respir Crit Care Med 1996; 154: 477-483.

16 Uhal BD, Joshi I, Hughes WF, Ramos C, Pardo A, Selman M. Alveolar epithelial cell death adjacent to underlying myofibroblasts in advanced fibrotic human lung. Am J Physiol 1998; 275: L1192-L1199.

17 Nakashima N, Kuwano K, Maeyama T, et al. The p53Mdm2 association in epithelial cells in idiopathic pulmonary fibrosis and non-specific interstitial pneumonia. J Clin Pathol 2005; 58: 583-589.

18 Inoshima I, Kuwano K, Hamada N, et al. Induction of CDK inhibitor p21 gene as a new therapeutic strategy against pulmonary fibrosis. Am J Physiol Lung Cell Mol Physiol 2004; 286: L727-L733.

19 Plataki M, Koutsopoulos AV, Darivianaki K, Delides G, Siafakas NM, Bouros D. Expression of apoptotic and antiapoptotic markers in epithelial cells in idiopathic pulmonary fibrosis. Chest 2005; 127: 266-274.

20 Desmouliere A. Factors influencing myofibroblast differentiation during wound healing and fibrosis. Cell Biol Int 1995; 19: 471-476.

21 Moodley YP, Caterina P, Scaffidi AK, et al. Comparison of the morphological and biochemical changes in normal human lung fibroblasts and fibroblasts derived from lungs of patients with idiopathic pulmonary fibrosis during FasL-induced apoptosis. J Pathol 2004; 202: 486-495.

22 Tanaka T, Yoshimi M, Maeyama T, Hagimoto N, Kuwano K, Hara N. Resistance to Fas-mediated apoptosis in human lung fibroblast. Eur Respir J 2002; 20: 359-368.

23 Buhling F, Wille A, Röcken C, et al. Altered expression of membrane-bound and soluble CD95/Fas contributes to the resistance of fibrotic lung fibroblasts to FasL induced apoptosis. Respir Res 2005; 6: 37.

24 Avivi-Green C, Singal M, Vogel WF. Discoidin domain receptor 1-deficient mice are resistant to bleomycin-induced lung fibrosis. Am J Respir Crit Care Med 2006; 174: 420-427.
25 Horowitz JC, Rogers DS, Sharma V, et al. Combinatorial activation of FAK and AKT by transforming growth factorbeta1 confers an anoikis-resistant phenotype to myofibroblasts. Cell Signal 2007; 19: 761-771.

26 Sanders YY, Kumbla P, Hagood JS. Enhanced myofibroblastic differentiation and survival in Thy-1 $1^{-}$lung fibroblasts. Am J Respir Cell Mol Biol 2007; 36: 226-235.

27 Young LR, Pasula R, Gulleman PM, Deutsch GH, McCormack FX. Susceptibility of Hermansky-Pudlak mice to bleomycin-induced type II cell apoptosis and fibrosis. Am J Respir Cell Mol Biol 2007; 37: 67-74.

28 Hamilton RF Jr, Li L, Felder TB, Holian A. Bleomycin induces apoptosis in human alveolar macrophages. Am J Physiol 1995; 269: L318-L325.

29 Zhao HW, Hu SY, Barger MW, Ma JK, Castranova V, Ma JY. Time-dependent apoptosis of alveolar macrophages from rats exposed to bleomycin: involvement of TNF receptor 2. J Toxicol Environ Health A 2004; 67: 1391-1406.

30 Wang L, Antonini JM, Rojanasakul Y, Castranova V, Scabilloni JF, Mercer RR. Potential role of apoptotic macrophages in pulmonary inflammation and fibrosis. $J$ Cell Physiol 2003; 194: 215-224.

31 Wang L, Scabilloni JF, Antonini JM, Rojanasakul Y, Castranova V, Mercer RR. Induction of secondary apoptosis, inflammation, and lung fibrosis after intratracheal instillation of apoptotic cells in rats. Am J Physiol Lung Cell Mol Physiol 2006; 290: L695-L702.

32 Kuwano K, Hagimoto N, Tanaka T, et al. Expression of apoptosis-regulatory genes in epithelial cells in pulmonary fibrosis in mice. J Pathol 2000; 190: 221-229.

33 Kuwano K, Miyazaki H, Hagimoto N, et al. The involvement of Fas-Fas ligand pathway in fibrosing lung diseases. Am J Respir Cell Mol Biol 1999; 20: 53-60.

34 Mermigkis CM, Tsakanika K, Polychronopoulos V, Karagianidis N, Mermigkis G, Bouros D. Expression of bcl-2 protein in bronchoalveolar lavage cell populations from patients with idiopathic pulmonary fibrosis. Acta Cytol 2001; 45: 914-918.

35 Baran CP, Opalek JM, McMaken S, et al. Important roles for M-CSF, CCL2 and mononuclear phagocytes in the pathogenesis of pulmonary fibrosis. Am J Respir Crit Care Med 2007; 176: 78-89.

36 Wynes MW, Frankel SK, Riches DW. IL-4-induced macrophage-derived IGF-I protects myofibroblasts from apoptosis following growth factor withdrawal. J Leukoc Biol 2004; 76: 1019-1027.

37 Bianchi SM, Dockrell DH, Renshaw SA, Sabroe I, Whyte MK. Granulocyte apoptosis in the pathogenesis and resolution of lung disease. Clin Sci (Lond) 2006; 110: 293-304.

38 Turner-Warwick M, Haslam PL. The value of serial bronchoalveolar lavages in assessing the clinical progress of patients with cryptogenic fibrosing alveolitis. Am Rev Respir Dis 1987; 135: 26-34.

39 Li HP, Li X, He GJ, Yi XH, Kaplan AP. The influence of dexamethasone on the proliferation and apoptosis of pulmonary inflammatory cells in bleomycin-induced pulmonary fibrosis in rats. Respirology 2004; 9: 25-32.

40 Watters LC, Schwarz MI, Cherniack RM, et al. Idiopathic pulmonary fibrosis. Pretreatment bronchoalveolar lavage cellular constituents and their relationships with lung 
histopathology and clinical response to therapy. Am Rev Respir Dis 1987; 135: 696-704.

41 Thrall RS, Phan SH, McCormick JR, Ward PA. The development of bleomycin-induced pulmonary fibrosis in neutrophil-depleted and complement-depleted rats. Am J Pathol 1981; 105: 76-81.

42 Maher TM, Wells AU, Laurent GJ. Idiopathic pulmonary fibrosis: multiple causes and multiple mechanisms? Eur Respir J 2007; 30: 835-839.

43 McWhinnie R, Pechkovsky DV, Zhou D, et al. Endothelin-1 induces hypertrophy and inhibits apoptosis in human airway smooth muscle cells. Am J Physiol Lung Cell Mol Physiol 2007; 292: L278-L286.

44 Jain R, Shaul PW, Borok Z, Willis BC. Endothelin-1 induces alveolar epithelial-mesenchymal transition through endothelin type A receptor-mediated production of TGFbeta1. Am J Respir Cell Mol Biol 2007; 37: 38-47.

$45 \mathrm{Li} \mathrm{X,} \mathrm{Molina-Molina} \mathrm{M,} \mathrm{Abdul-Hafez} \mathrm{A,} \mathrm{et} \mathrm{al.}$ Extravascular sources of lung angiotensin peptide synthesis in idiopathic pulmonary fibrosis. Am J Physiol Lung Cell Mol Physiol 2006; 291: L887-L895.

46 Wang R, Ramos C, Joshi I, et al. Human lung myofibroblast-derived inducers of alveolar epithelial apoptosis identified as angiotensin peptides. Am J Physiol 1999; 277: L1158-L1164.

47 Wang R, Zagariya A, Ang E, Iburra-Sunga O, Uhal BD. Fas-induced apoptosis of alveolar epithelial cells requires ANG II generation and receptor interaction. Am J Physiol 1999; 277: L1245-1250.

48 Uhal BD, Gidea C, Bargout R, et al. Captopril inhibits apoptosis in human lung epithelial cells: a potential antifibrotic mechanism. Am J Physiol 1998; 275: L1013-L1017.

49 Li X, Rayford H, Uhal BD. Essential roles for angiotensin receptor AT1a in bleomycin-induced apoptosis and lung fibrosis in mice. Am J Pathol 2003; 163: 2523-2530.

50 Li X, Zhuang J, Rayford H, Zhang H, Shu R, Uhal BD. Attenuation of bleomycin-induced pulmonary fibrosis by intratracheal administration of antisense oligonucleotides against angiotensinogen mRNA. Curr Pharm Des 2007; 13: 1257-1268.

51 Kuwano K, Nakashima N, Inoshima I, et al. Oxidative stress in lung epithelial cells from patients with idiopathic interstitial pneumonias. Eur Respir J 2003; 21: 232-240.

52 Waghray M, Cui Z, Horowitz JC, et al. Hydrogen peroxide is a diffusible paracrine signal for the induction of epithelial cell death by activated myofibroblasts. FASEB J 2005; 19: 854-856.

53 Wallach-Dayan SB, Izbicki G, Cohen PY, Gerstl-Golan R, Fine A, Breuer R. Bleomycin initiates apoptosis of lung epithelial cells by ROS but not by Fas/FasL pathway. Am J Physiol Lung Cell Mol Physiol 2006; 290: L790-L796.

54 Psathakis K, Mermigkis D, Papatheodorou G, et al. Exhaled markers of oxidative stress in idiopathic pulmonary fibrosis. Eur J Clin Invest 2006; 36: 362-367.

55 Davis DW, Weidner DA, Holian A, McConkey DJ. Nitric oxide-dependent activation of p53 suppresses bleomycininduced apoptosis in the lung. J Exp Med 2000; 192: 857-869.

56 Takahashi A, Aoshiba K, Nagai A. Apoptosis of wound fibroblasts induced by oxidative stress. Exp Lung Res 2002; 28: 275-284.
57 Krick S, Eul BG, Hänze J, et al. Role of hypoxia-inducible factor- $1 \alpha$ in hypoxia-induced apoptosis of primary alveolar epithelial type II cells. Am J Respir Cell Mol Biol 2005; 32: 395-403.

58 Tzouvelekis A, Harokopos V, Paparountas T, et al. Comparative expression profiling in pulmonary fibrosis suggests a role of hypoxia-inducible factor-1alpha in disease pathogenesis. Am J Respir Crit Care Med 2007; 176: 1108-1119.

59 Kim KK, Kugler MC, Wolters PJ, et al. Alveolar epithelial cell mesenchymal transition develops in vivo during pulmonary fibrosis and is regulated by the extracellular matrix. Proc Natl Acad Sci USA 2006; 103: 13180-13185.

60 Zhu YK, Umino T, Liu XD, et al. Contraction of fibroblastcontaining collagen gels: initial collagen concentration regulates the degree of contraction and cell survival. In Vitro Cell Dev Biol Anim 2001; 37: 10-16.

61 Hadden HL, Henke CA. Induction of lung fibroblast apoptosis by soluble fibronectin peptides. Am J Respir Crit Care Med 2000; 162: 1553-1560.

62 Farias E, Lu M, Li X, Schnapp LM. Integrin $\alpha 8 \beta 1-$ fibronectin interactions promote cell survival via PI3 kinase pathway. Biochem Biophys Res Commun 2005; 329: 305-311.

63 Antoniou KM, Alexandrakis MG, Siafakas NM, Bouros D. Cytokine network in the pathogenesis of idiopathic pulmonary fibrosis. Sarcoidosis Vasc Diffuse Lung Dis 2005; 22: 91-104.

64 Hagimoto N, Kuwano K, Inoshima I, et al. TGF- $\beta 1$ as an enhancer of Fas-mediated apoptosis of lung epithelial cells. J Immunol 2002; 168: 6470-6478.

65 Yamada M, Kuwano K, Maeyama T, et al. Gene transfer of soluble transforming growth factor type II receptor by in vivo electroporation attenuates lung injury and fibrosis. $J$ Clin Pathol, 2007; 60: 916-920.

66 Budinger GR, Mutlu GM, Eisenbart J, et al. Proapoptotic Bid is required for pulmonary fibrosis. Proc Natl Acad Sci USA 2006; 103: 4604-4609.

67 Kang HR, Cho SJ, Lee CG, Homer RJ, Elias JA. Transforming growth factor (TGF)- $\beta 1$ stimulates pulmonary fibrosis and inflammation via a Bax-dependent, Bidactivated pathway that involves matrix metalloproteinase12. J Biol Chem 2007; 282: 7723-7732.

68 Yamasaki M, Kang HR, Homer RJ, et al. P21 regulates TGF$\beta 1$-induced pulmonary responses via a TNF- $\alpha$ signaling pathway. Am J Respir Cell Mol Biol 2008; 38: 346-353.

69 Kapoun AM, Gaspar NJ, Wang Y, et al. Transforming growth factor- $\beta$ receptor type 1 (TGF $\beta R I$ ) kinase activity but not p38 activation is required for TGF $\beta R I$-induced myofibroblast differentiation and profibrotic gene expression. Mol Pharmacol 2006; 70: 518-531.

70 Frankel SK, Cosgrove GP, Cha SI, et al. TNF-alpha sensitizes normal and fibrotic human lung fibroblasts to Fas-induced apoptosis. Am J Respir Cell Mol Biol 2006; 34: 293-304.

71 Voll RE, Herrmann M, Roth EA, Stach C, Kalden JR, Girkontaite I. Immunosuppressive effects of apoptotic cells. Nature 1997; 390: 350-351.

72 Gao Y, Herndon JM, Zhang H, Griffith TS, Ferguson TA. Antiinflammatory effects of CD95 ligand (FasL)-induced apoptosis. J Exp Med 1998; 188: 887-896. 
73 Brown SB, Savill J. Phagocytosis triggers macrophage release of Fas ligand and induces apoptosis of bystander leukocytes. J Immunol 1999; 162: 480-485.

74 Gregory CD, Devitt A. The macrophage and the apoptotic cell: an innate immune interaction viewed simplistically? Immunology 2004; 113: 1-14.

75 Chambers RC. Procoagulant signalling mechanisms in lung inflammation and fibrosis: novel opportunities for pharmacological intervention? Br J Pharmacol 2008; 153: Suppl. 1, S367-S378.

76 Kubo H, Nakayama K, Yanai M, et al. Anticoagulant therapy for idiopathic pulmonaryfibrosis. Chest 2005; 128 : 1475-1482.

77 Suzuki T, Moraes TJ, Vachon E, et al. Proteinase-activated receptor-1 mediates elastase-induced apoptosis of human lung epithelial cells. Am J Respir Cell Mol Biol 2005; 33: 231-247.

78 Jenkins RG, Su X, Su G, et al. Ligation of protease-activated receptor 1 enhances $\alpha_{v} \beta_{6}$ integrin-dependent TGF- $\beta$ activation and promotes acute lung injury. J Clin Invest 2006; 116: 1606-1614.

79 Brantly M, Avila NA, Shotelersuk V, Lucero C, Huizing M, Gahl WA. Pulmonary function and high-resolution CT findings in patients with an inherited form of pulmonary fibrosis, Hermansky-Pudlak syndrome, due to mutations in HPS-1. Chest 2000; 117: 129-136.

80 Campisi J. Senescent cells, tumour suppression, and organismal aging: good citizens, bad neighbors. Cell 2005; 120: 513-522.

81 Lee PJ, Alam J, Sylvester SL, Inamdar N, Otterbein L, Choi AM. Regulation of heme oxygenase-1 expression in vivo and in vitro in hyperoxic lung injury. Am J Respir Cell Mol Biol 1996; 14: 556-568.

82 Marcotte R, Lacelle C, Wang E. Senescent fibroblasts resist apoptosis by downregulating caspase-3. Mech Ageing Dev 2004; 125: 777-783.

83 Blasco MA. Telomere length, stem cells and aging. Nat Chem Biol 2007; 3: 640-649.

84 Tsakiri KD, Cronkhite JT, Kuan PJ, et al. Adult-onset pulmonary fibrosis caused by mutations in telomerase. Proc Natl Acad Sci USA 2007; 104: 7552-7557.

85 Fridlender ZG, Cohen PY, Golan O, Arish N, WallachDayan S, Breuer R. Telomerase activity in bleomycininduced epithelial cell apoptosis and lung fibrosis. Eur Respir J 2007; 30: 205-213.

86 Liu T, Chung MJ, Ullenbruch M, et al. Telomerase activity is required for bleomycin-induced pulmonary fibrosis in mice. J Clin Invest 2007; 117: 3800-3809. 